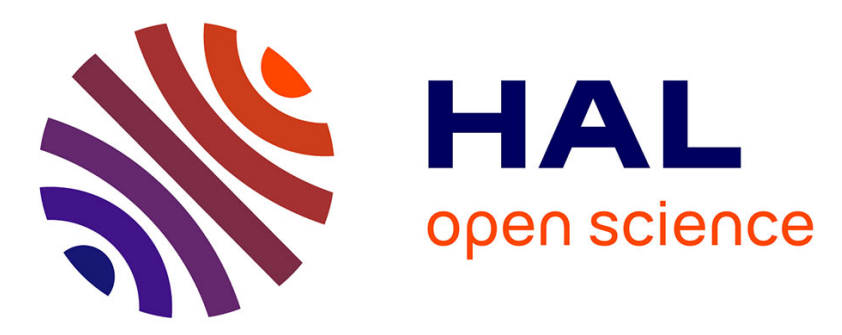

\title{
In Situ Formation of Strain Sensors by Breaking Optical Fibers in Structural Materials
}

Hiroshi Asanuma, Osamu Haga, Kazuhito Kimura, Jun-Ichiro Ohira, Haruki Kurihara, Antonio Paolozzi

\section{- To cite this version:}

Hiroshi Asanuma, Osamu Haga, Kazuhito Kimura, Jun-Ichiro Ohira, Haruki Kurihara, et al.. In Situ Formation of Strain Sensors by Breaking Optical Fibers in Structural Materials. Journal of Thermoplastic Composite Materials, 2006, 19 (3), pp.277-292. 10.1177/0892705706063920 . hal00570803

\section{HAL Id: hal-00570803 https://hal.science/hal-00570803}

Submitted on 1 Mar 2011

HAL is a multi-disciplinary open access archive for the deposit and dissemination of scientific research documents, whether they are published or not. The documents may come from teaching and research institutions in France or abroad, or from public or private research centers.
L'archive ouverte pluridisciplinaire HAL, est destinée au dépôt et à la diffusion de documents scientifiques de niveau recherche, publiés ou non, émanant des établissements d'enseignement et de recherche français ou étrangers, des laboratoires publics ou privés. 


\title{
In Situ Formation of Strain Sensors by Breaking Optical Fibers in Structural Materials
}

\author{
Hiroshi Asanuma, * Osamu Haga, Kazuhito Kimura, \\ JUN-ICHIRO OHIRA, HARUKI KURIHARA \\ Department of Electronics and Mechanical Engineering \\ Faculty of Engineering, Chiba University, 1-33, Yayoicho \\ Inage-ku, Chiba-shi, Chiba 263-8522, Japan \\ ANTONIO PAOLOZZI \\ Department of Aerospace and Astronautical Engineering \\ School of Aerospace Engineering, Università "La Sapienza" \\ di Roma, Via Eudossiana 18, 00184 Roma, Italy
}

\begin{abstract}
This article describes the formation of strain sensors embedded in a matrix material by breaking a notched optical fiber in the matrix. When a specimen with an embedded optical fiber with a notch is tensile tested, fracture of the fiber at the notch occurs, producing an optical interference type strain sensor. During the formation process optical transmission loss is recorded. The case of multiply notched optical fibers is also considered and it is shown that the optical loss of the embedded optical fiber during tensile test increases with the number of breaks. Using bending, instead of tension, to form the sensor, allows a reduction of break pitch and consequently improves the local nature of the sensor. The multiple fractured type optical fiber sensor has also been used on an active laminate to monitor its curvature change during actuation.
\end{abstract}

KEY WORDS: smart material, optical fiber, composite, strain sensor, active material.

*Author to whom correspondence should be addressed.

E-mail: asanuma@faculty.chiba-u.jp; antonio.paolozzi@uniroma1.it

Figures 1-6 appear in color online: http://jtc.sagepub.com

Journal of Thermoplastic COMPosite Materials, Vol. 19-May 2006 


\title{
INTRODUCTION
}

\begin{abstract}
A DVANCED STRUCTURAL MATERIALS with embedded sensors are attracting worldwide interest because of their innovative functions such as health monitoring [1-4] as well as shape monitoring and control $[5,6]$. Fiber optic sensors in particular offer several advantages over the conventional ones: they are immune from electromagnetic interferences, they are small, and made of glass which is an insulating material. This last aspect is very convenient when the embedding is performed in metallic materials. Furthermore, the specific weight is much lower than copper. Various types of sophisticated fiber optic sensors have been developed such as the Fiber Fabry Perot Interferometer (FFPI) and the Fiber Bragg Gratings (FBGs) [7-9]. Also embedding procedures for those sensors have been tested in high performance structural materials such as composites. Embedding in metals, ceramics, and concrete have been performed successfully as shown in [10-12].

A simple and effective optical interference or loss type sensor is tested in this work. The concept, proposed by Asanuma [13,14] is shown in Figure 1. The sensor can be obtained by breaking a notched optical fiber embedded in a material. The sensing part is formed inside the material without the need of alignment of the fiber optical axis, a tube for the alignment, and an adhesive for fixing the tube. A simple, compact, robust, and low cost fiber optic sensor can be easily obtained. The purpose of this study is to demonstrate the concept and examine the performances of this new sensor. The active laminate, already proposed in [15] is also used to show a possible application of this new type of sensor.
\end{abstract}

\section{EXPERIMENTAL}

\section{Formation of Sensors in Epoxy Matrix}

A quartz type and single mode optical fiber (produced by Fujikura Co., Ltd.) was used. Fiber diameter was $250 \mu \mathrm{m}$, including the acrilate coating (125 $\mu \mathrm{m}$ without coating). Notches were made on the optical fiber with an optical fiber cutter. Epoxy resin (Araldite CY230) was used for the material. The curing temperature and period were $393 \mathrm{~K}$ and $3.6 \mathrm{ks}$, respectively.

Number of notches and their distances on the optical fiber are expressed as $n$ and $s$, respectively, as shown in Figure 1. The $n$ and $s$ were varied from 1 to 15 and 0.5 to $10 \mathrm{~mm}$, respectively. Optical fibers with the notches were embedded in the epoxy resin. A tensile sample, shown in Figure 2(a), and a bending sample, shown in Figure 2(b), were made. For the higher number of $n$ and $s$ the gage length needed to be increased (for instance in 
(a)

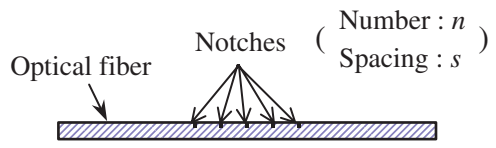

(b)

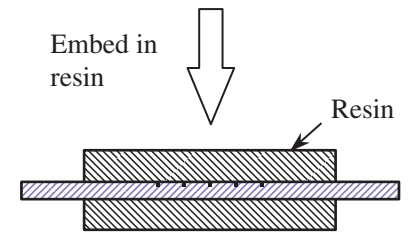

(c)

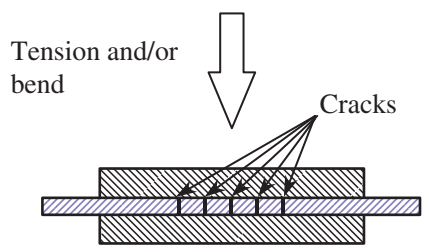

Figure 1. Concept for in situ formation of fiber-optic strain sensors.

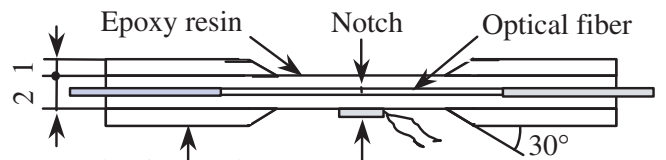

Aluminum tab Strain gage

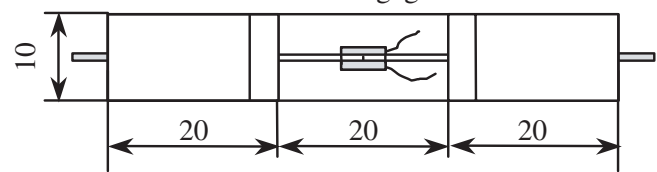

(a) Tensile test
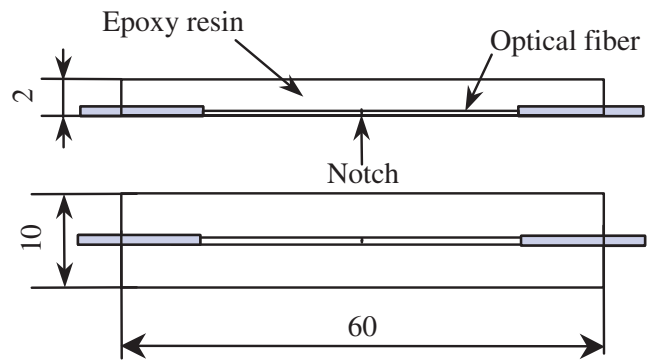

(b) Bending test

Figure 2. Shapes and dimensions of the test pieces (in $\mathrm{mm}$ ). 
the case of $n=10$ and 15 at $s=4 \mathrm{~mm}$ the gage length was increased to 40 and $60 \mathrm{~mm}$, respectively).

Tensile test was undertaken by using an Instron type machine at room temperature under the crosshead speed of $0.1 \mathrm{~mm} / \mathrm{min}$. Bending test was undertaken by using the same testing machine, a $90^{\circ} \mathrm{V}$ block, and an $\mathrm{R}$ type punch with a radius of $5 \mathrm{~mm}$. The test piece was put on the block so that the embedded optical fiber was above the neutral axis.

In both the tensile and bending tests, one end of the embedded optical fiber was connected to an LD light source of $0.67 \mu \mathrm{m}$ wavelength and the other end was connected to a light power meter.

\section{Formation of Sensors in Active Laminate}

The materials used to fabricate the active laminate are shown in Table 1. The aluminum plate was used as the high coefficient of thermal expansion (CTE) material while the carbon fiber reinforced plastics (CFRP) prepreg was used as the low CTE material and the heater. An epoxy adhesive film was used as the insulator between them, while the copper foils were used, in two opposite edges of the laminate, as the electrodes to apply a voltage on the CFRP laminate. When current flows in the carbon fiber of the CFRP laminate, heat is produced by the Joule effect. Heat propagates on the aluminum plate as well causing its expansion. On the other hand, CFRP due to the negative CTE of carbon fibers has a negligible deformation. As a consequence the active laminate bends.

To manufacture the sensor, 15 notches with $s=3 \mathrm{~mm}$ were made on an optical fiber. Then the notched optical fiber was placed between the plies of the CFRP prepregs to form the laminate. Copper foils were also included, as shown in Figure 3(a), to provide the electrical contact required during operation. This pile was hot-pressed at $453 \mathrm{~K}, 0.1 \mathrm{MPa}$ for $7.2 \mathrm{ks}$.

Table 1. Materials used to manufacture the active laminate.

\begin{tabular}{|c|c|c|c|}
\hline Material & CTE $\alpha\left(10^{-6} \mathrm{~K}^{-1}\right.$ & ) Thickness, $t(\mathrm{~mm})$ & Type \\
\hline Aluminum plate & 23.6 & 0.2 & A1050P-H24 \\
\hline CFRP prepreg & 0.7 & 0.125 & $\begin{array}{l}\text { P3060B-12 (Fiber: } \\
\text { Torayca T300 }\left(V_{f}=0.6\right), \\
\text { Resin: } 453 \mathrm{~K} \text { cure type } \\
\text { epoxy resin }(\# 3601)) \\
\text { produced by Toray Co., Ltd. }\end{array}$ \\
\hline Epoxy adhesive film & 60 & 0.25 & $\begin{array}{l}\text { Redux } 319 \text { produced by } \\
\text { Hexcel Composites Ltd. }\end{array}$ \\
\hline Copper foil & 16.5 & 0.02 & C1100 \\
\hline
\end{tabular}


Next, this consolidated layer was bent with a rod as shown in Figure 3(b) to break the embedded optical fiber at the notches while monitoring optical loss through the LD light source of $0.67 \mu \mathrm{m}$ wavelength and the power meter. Finally, this laminate was completed with the adhesive film, which is known to be important also for providing electrical insulation, and the aluminum plate (Figure 4(a)). This hybrid laminate is then hot-pressed at $448 \mathrm{~K}$, under $0.1 \mathrm{MPa}$ for $3.6 \mathrm{ks}$. The result is the active laminate with the embedded optical fiber sensor (Figure 4(b)).

In Figure 5, a schematic diagram of the curvature and optical loss measurement system is shown. The active laminate was put on a $90^{\circ} \mathrm{V}$ block having supporting edges of $50 \mathrm{~mm}$ span and its embedded optical fiber was connected to the LD light source and the power meter. Subsequently, the laminate was heated by connecting the electric power source to

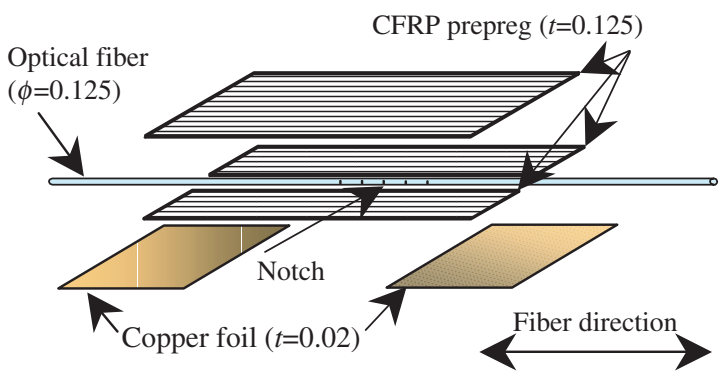

(a) Lamination

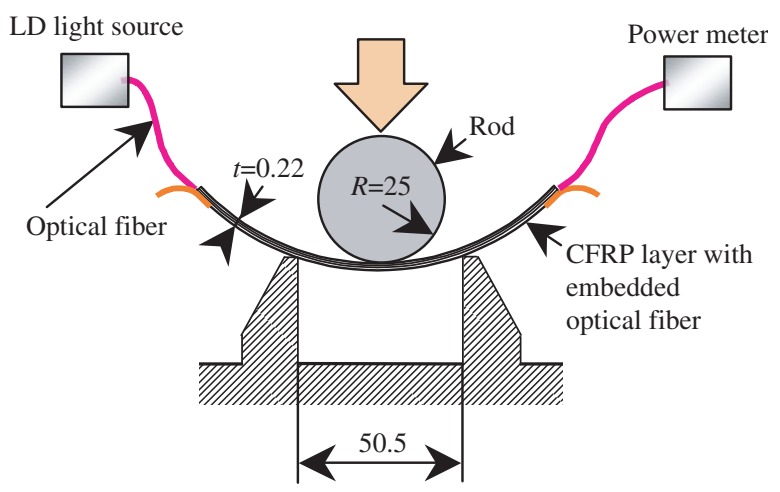

(b) Bending

Figure 3. Method to introduce the optical loss type sensor in the CFRP layer: (a) lamination of the materials to form a CFRP layer embedded with a notched optical fiber and (b) bending of the CFRP layer to cause fractures of its embedded optical fiber at the notches. (Dimensions indicated are in $\mathrm{mm}$.) 


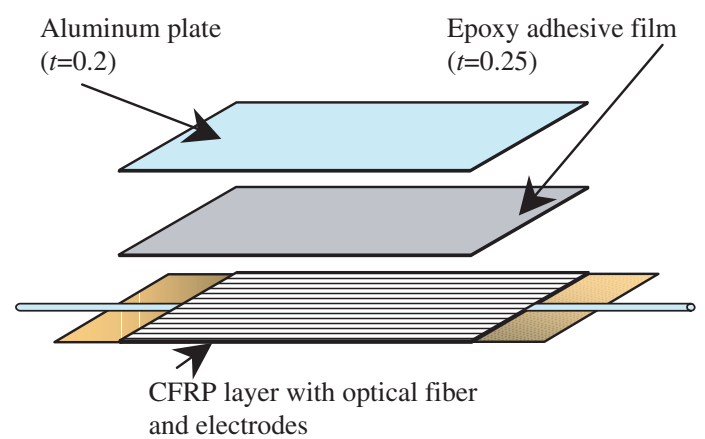

(a) Lamination

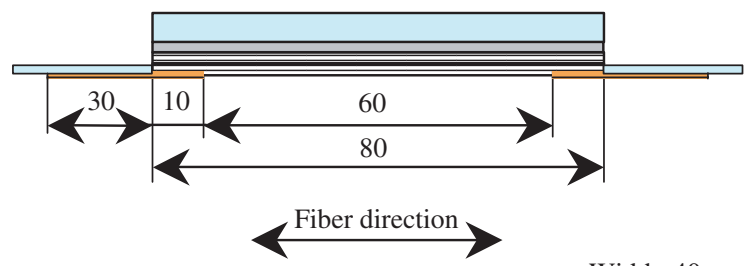

(b) The final product

Width: 40

Figure 4. Lamination of the CFRP layer with the other materials to form the active laminate with the embedded optical fiber sensor. (Dimensions are in $\mathrm{mm}$.)

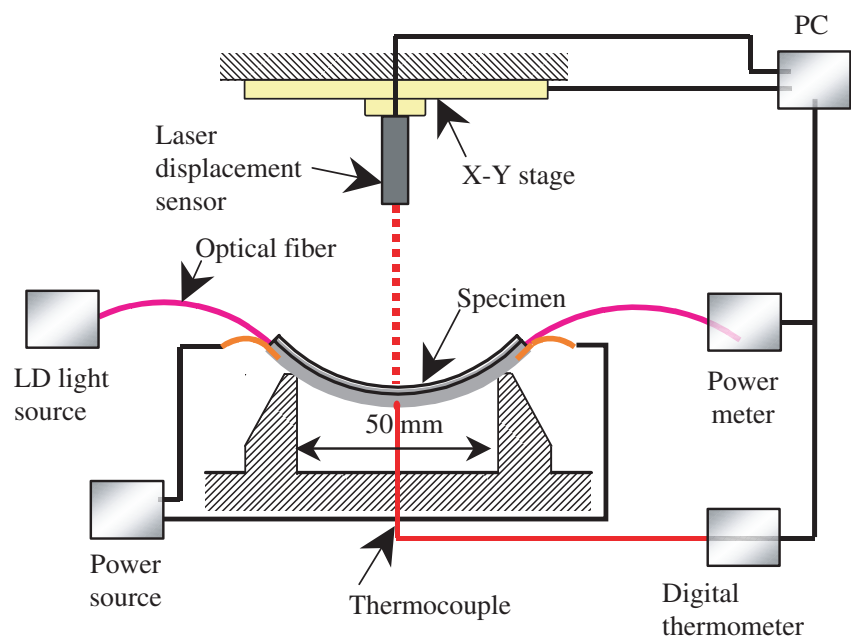

Figure 5. Schematic diagram of the curvature and optical loss measurement system for the active laminate. 
the CFRP layer through the copper foils. The change in curvature is independently measured by monitoring the central point and the other two points near the supporting edges on the specimen surface. Coordinates of these three points were measured with the laser displacement sensor attached to the $\mathrm{X}-\mathrm{Y}$ stage. Average curvature of the specimen was calculated taking the inverse of the radius of the circle passing through those three points. Variation of the optical loss during the curvature change was monitored.

\section{RESULTS AND DISCUSSION}

\section{Tensile Test on Optical Fiber}

A notch made with the optical fiber cutter is shown in Figure 6. As shown in this figure, length of the notch is about $50 \mu \mathrm{m}$, so, knowing the fiber diameter, it is easy to calculate the depth of the notch as $5.2 \mu \mathrm{m}$. Tensile strengths of the undamaged optical fiber and with a notch are compared in Figure 7. From the figure, it is clear that the average tensile strength is drastically decreased from $1.52 \mathrm{GPa}$ to $1.25 \mathrm{MPa}$ due to the introduction of the notch. To avoid fiber breakage at the jaws of the tensile machine, the fiber was fully accommodated on a groove manufactured on the tabs. Resin was used to block the fiber on the tabs.

\section{Forming the Optical Interference Type Strain Sensor}

An epoxy resin specimen with an embedded notched optical fiber was tensile tested while monitoring optical transmission loss. In Figure 8, the optical transmission loss and tensile strain versus time in the case of $n=1$ is shown. According to the figure, the optical loss remains constant up to around $100 \mathrm{~s}$, that is, at the strain of $0.55 \%$, and then it starts to fluctuate sinusoidally. This result means that the optical fiber breaks at the strain of $0.55 \%$ and that the fracture surfaces are parallel to each other and normal to the optical axis. The two surfaces work as mirrors to cause optical interference that changes output light intensity while changing spacing between them. The optical fiber breaks at the location of the notch and the subsequent variation of optical power is also visually observed because the epoxy resin test piece is transparent and the leaked laser light is visible. Therefore, the fractured part is available as an optical interference type strain sensor, and the result clarified the effectiveness of the concept shown in Figure 1. The main difference between the proposed sensor and an FFPI is in the manufacturing process that is more complex for the FFPI and in the fact that usually only one FFPI is used in the fiber. In the proposed 


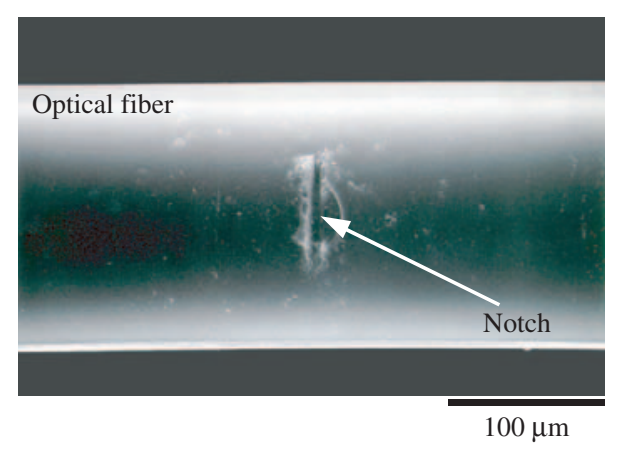

Figure 6. Optical fiber with a notch.

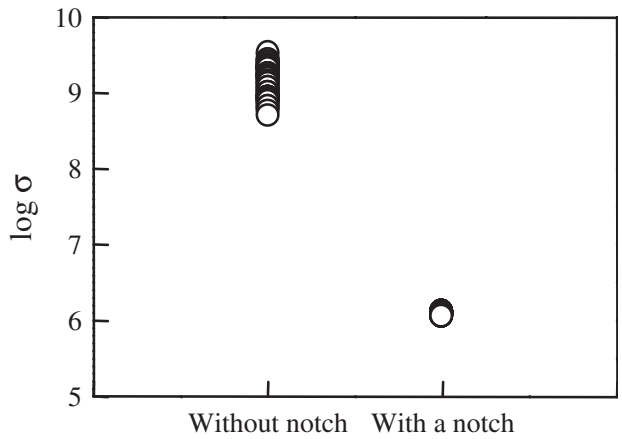

Figure 7. Tensile strengths of the optical fibers with and without a notch.

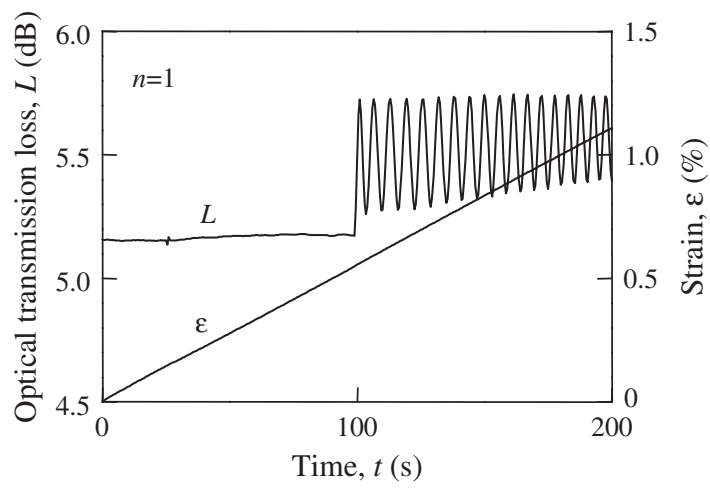

Figure 8. Optical transmission loss and tensile strain of a test piece with one notch $(n=1)$ as a function of time. 
sensor there is a series of FFPI in cascade along the same fiber. The power transmitted by a single FFPI is, under certain simplified assumption:

$$
I_{t}=I_{0} \frac{\left(1-r^{2}\right)^{2}}{\left[\left(1-r^{2}\right)^{2}+4 r^{2} \sin ^{2}(k a)\right]}
$$

where $I_{0}$ is the light intensity before entering the FFPI, $I_{\mathrm{t}}$ is the light intensity after entering the FFPI, $r$ is the reflection coefficient of the surface at the FFPI, $k=2 \pi / \lambda$ the wavenumber, and $a$ is the distance between the two faces of the FFPI.

\section{Tensile Test}

In order to obtain a multiply fractured optical fiber in a material, spacing between the notches, $s$ has to be equal to or larger than a critical length. Tensile test pieces were made to investigate the effect of $s$ on the number of fractures, that is, 1 or 2 . So, the spacing $s$ between the two notches was varied between 1 and $10 \mathrm{~mm}$. If the optical fiber breaks at both notches, the spacing $s$ is large enough to cause its multiple fractures.

An example of results of the tensile test in the case of $n=2$ and $s=10 \mathrm{~mm}$ is shown in Figure 9. According to the result, the optical fiber is broken at both notches in succession, and the light transmission loss caused by interference shows a jump at about $140 \mathrm{~s}$.

In Table 2, the number of specimens in which 1 or 2 breaks occurred is reported as a function of the spacing $s$ between the two notches. According to the results, the embedded optical fiber having two notches $(n=2)$ always breaks at both notches when $s$ is equal to or larger than $4 \mathrm{~mm}$. So the spacing $s$ was selected at $4 \mathrm{~mm}$ to obtain multiple fractures.

In Figure 10, the optical loss and the strain versus time is shown for different number of notches $n$ with constant spacing of $s=4 \mathrm{~mm}$. In the case of $n=5$, shown in Figure 10(a), the behavior is more complicated due to multiple fractures inside the same optical fiber. The oscillations are due to the interference occurring in the gap, analytically expressed by the $\sin ^{2}(k a)$ reported in the previous formula. When $n$ increases from 5 to 10 and 15 , the optical interference becomes more complicated, but the average value of the optical loss with increasing $n$ becomes closer to the behavior of the strain as shown in Figure 10(b) and (c). So the multiply fractured optical fiber in a material has a possibility to work as an optical loss type strain sensor.

The tensile test pieces, embedded with the multiply notched optical fiber, were loaded and unloaded for 4 cycles while monitoring the optical 


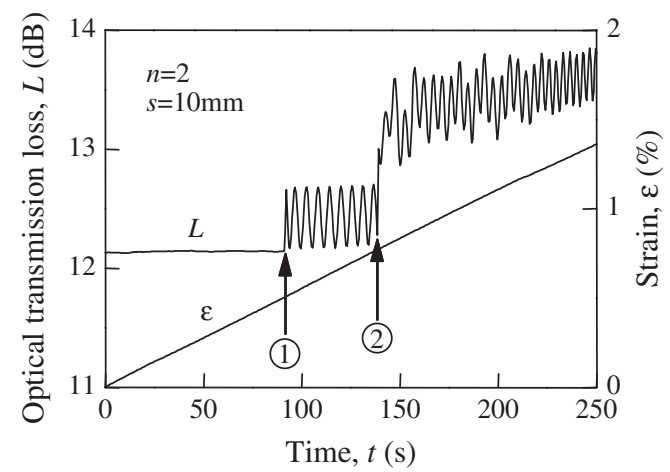

Figure 9. Optical transmission loss and tensile strain of a specimen with two notches $(n=2)$ and $s=10 \mathrm{~mm}$ as a function of time.

Table 2. Effect of spacing of notches s on number of tensile test results in which optical fiber broke at 1 or 2 of the notches.

\begin{tabular}{lcc}
\hline & \multicolumn{2}{c}{ Number of results } \\
\cline { 2 - 3 } Spacing of notches $\mathbf{s}(\mathbf{m m})$ & $\mathbf{1}$ fracture & $\mathbf{2}$ fracture \\
\hline 1 & 2 & 0 \\
2 & 1 & 3 \\
3 & 2 & 3 \\
4 & 0 & 4 \\
5 & 0 & 3 \\
10 & 0 & 3 \\
\hline
\end{tabular}

transmission losses. The results in the cases of $n=5,10$, and 15 are shown in Figure 11. The optical loss in the case of $n=5$ roughly follows the behavior of strain during testing as shown in Figure 11(a). An improvement is obtained by increasing $n$ to 10 and 15 as shown in Figure 11(b) and (c).

\section{Bending Test}

In order to decrease the critical fiber length and consequently notch distances, bending test was also performed. A bending test piece with an embedded optical fiber with $n=3$ and $s=0.5 \mathrm{~mm}$ was tested. The result is shown in Figure 12. According to the result, it is clear that the embedded optical fiber can be fractured into fragments as short as $0.5 \mathrm{~mm}$. So bending is more effective with respect to the density of breaks. 
(a)

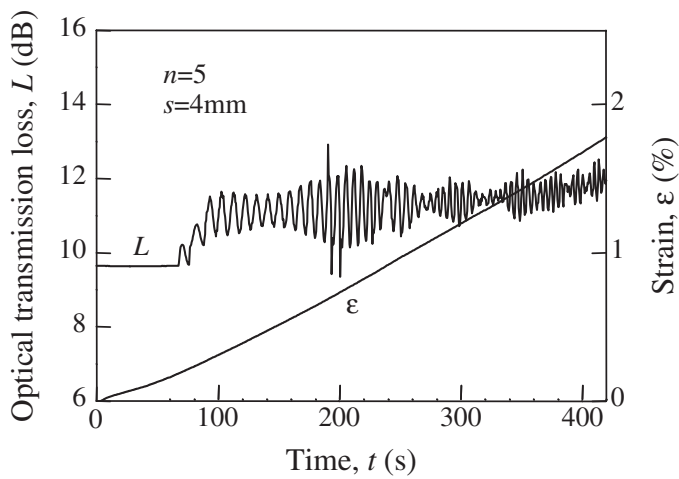

(b)

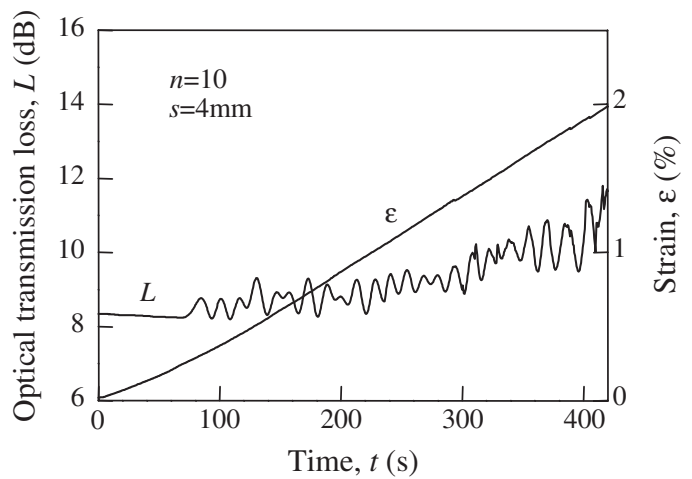

(c)

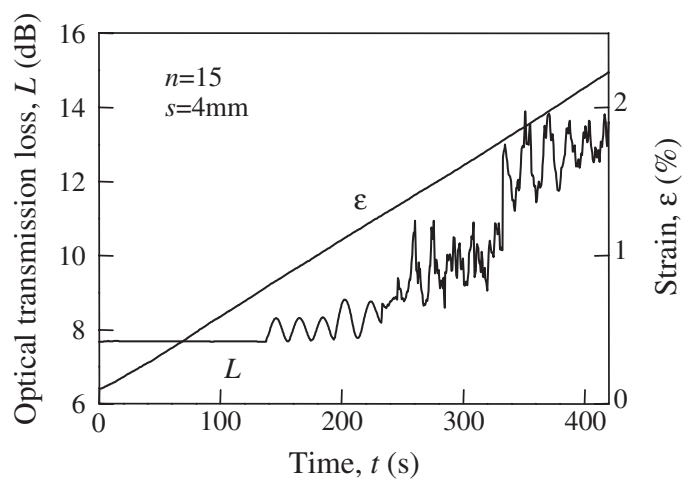

Figure 10. Optical transmission loss and tensile strain of test pieces with 5, 10, and 15 notches $(n=5,10,15)$ and $s=4 \mathrm{~mm}$ as a function of time.

\section{Optical Fiber Embedded in Active Laminate}

Notched optical fibers of $n=1$, and of $n=15$ and $s=3 \mathrm{~mm}$ were embedded in the CFRP layers as shown in Figure 3(a). The bending test 
(a)

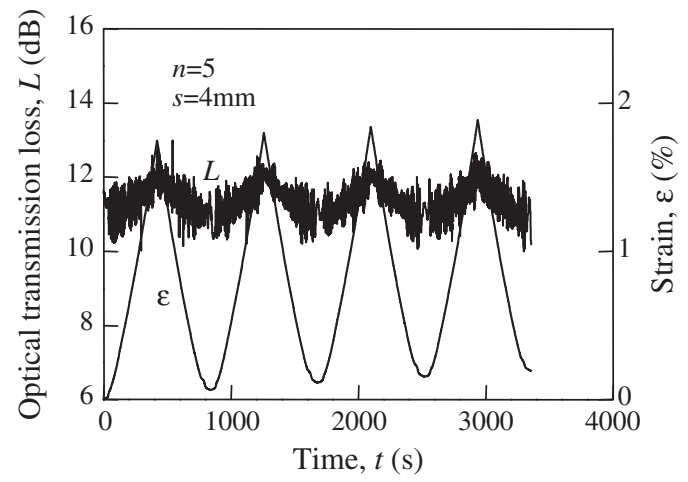

(b)

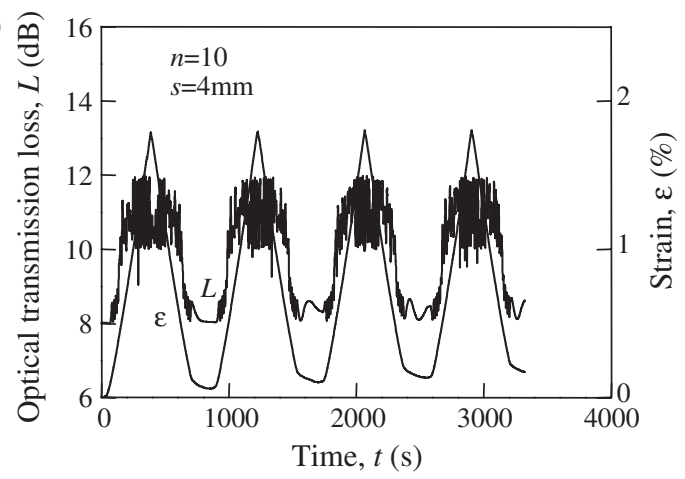

(c)

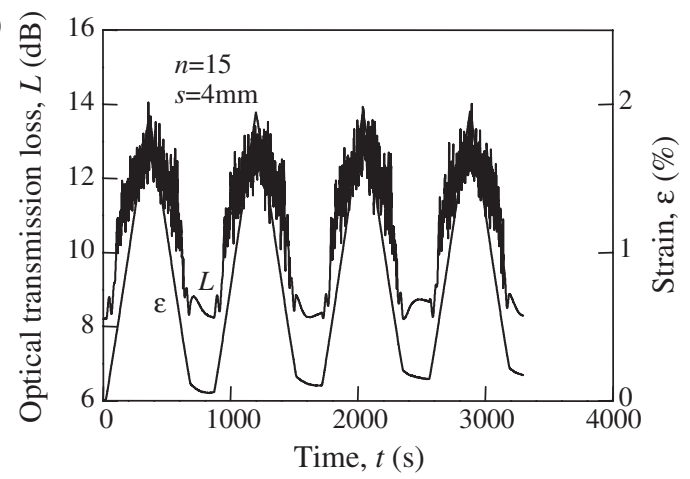

Figure 11. Optical transmission loss and tensile strain of test pieces with 5, 10, and 15 notches and $\mathrm{s}=4 \mathrm{~mm}$ as a function of time.

was performed with a punch of $25 \mathrm{~mm}$ radius as shown in Figure 3(b). The embedded optical fibers, as a consequence of the test, could break at each of the notches. These CFRP layers were then bonded with aluminum plates to obtain the active laminate as described in the section 


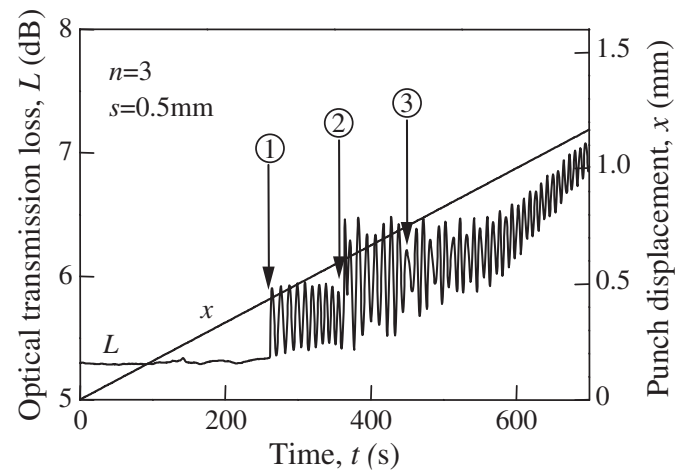

Figure 12. Bending test. Optical transmission loss of a test piece with 3 notches and $s=0.5 \mathrm{~mm}$. Punch displacement in $\mathrm{mm}$ as a function of time.

(a)

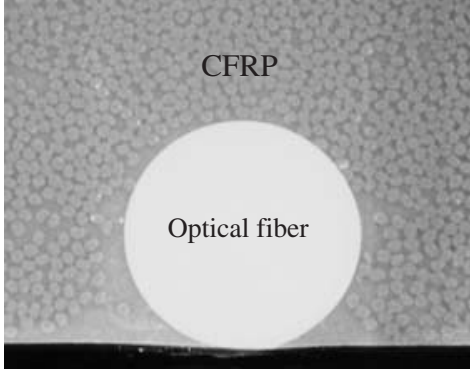

(b)

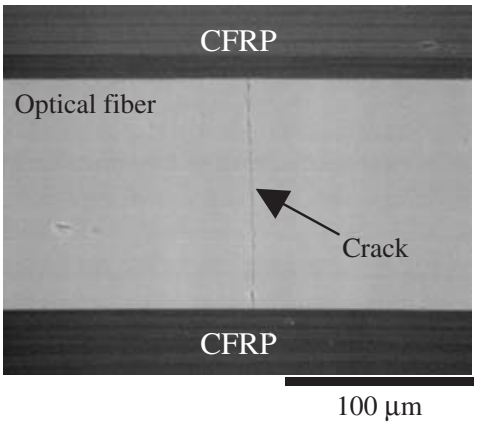

Figure 13. SEM images of: (a) a cross section and (b) a longitudinal section near the surface of the active laminate with the optical fiber.

titled 'Formation of Sensors in Active Laminate' and as shown in Figure 4. In Figure 13, a scanning electron micrograph of a cross section and of a longitudinal section of the active laminate are given. It can be seen that the optical fiber is placed adjacent to the free surface of 


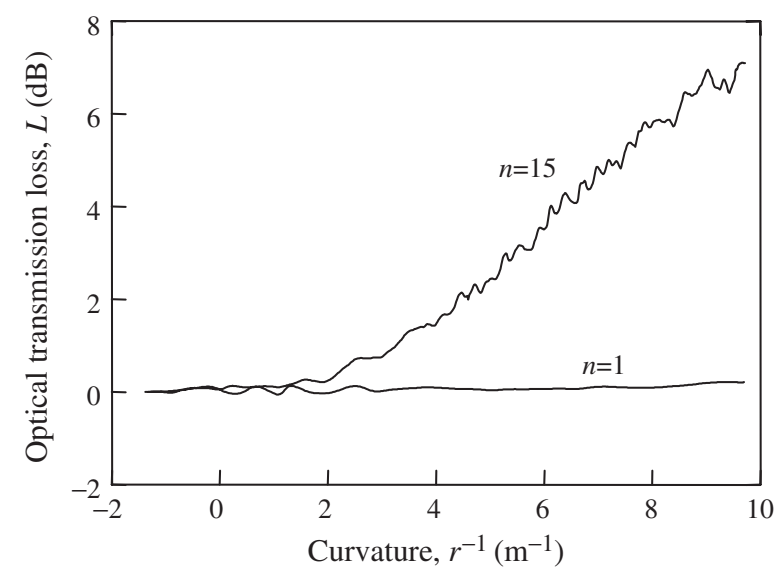

Figure 14. Effect of fracture number $n$ of embedded optical fiber on the relation between curvature and optical transmission loss of the active laminate.

the CFRP laminate. That means the fiber will be subjected to the largest tensile strain during subsequent bending tests. Figure 13 also shows a crack in the optical fiber.

In Figure 14, the effect of the number of notches $n$ of the embedded optical fiber on the relation between the curvature changed by heating of the CFRP layer and the optical transmission loss of the active laminate is shown. In agreement with what has already been shown in previous sections and in Figure 11 for the resin test samples, the higher number of notches, and ultimately of cracks, improves the sensing capability of the sensor. In fact according to Figure 14, the optical loss as a function of the curvature is clearly increased by the increase of the number $n$ from 1 to 15 . So the multiple breaks of the embedded optical fiber at its notches is effective to form a sensor for curvature monitoring of the active laminate and ultimately for its shape control.

\section{CONCLUSIONS}

1. An optical interference type strain sensor was successfully made in an epoxy resin test piece by breaking an embedded notched optical fiber by tensile test.

2. In the case of a multiply notched optical fiber, spacing of the notches was experimentally obtained as $4 \mathrm{~mm}$ in the case of tensile test.

3. Optical loss in the embedded optical fiber increases by increasing the number of fiber breaks from 5 to 15 . 
4. In the case of cyclic tests, performed on the specimens with embedded multiply fractured optical fibers, the optical losses follows the strain behavior better by increasing the number of the fiber fractures.

5. The pitch of the fiber breaks could be made as small as $0.5 \mathrm{~mm}$ by changing from tensile to bending tests.

6. The sensor, was successfully formed in the CFRP layer of the active laminate to monitor its curvature change during actuation.

\section{ACKNOWLEDGMENT}

A part of this research was supported by the Grant-in-Aid for Scientific Research on Priority Areas (B) by The Ministry of Education, Science, Sports and Culture under the area number of 725, and was also supported by the Japan Science and Technology Corporation. The authors thank Fujikura Ltd. for supplying the optical fibers.

\section{REFERENCES}

1. Chang, F.K. (2002). Ultra Reliable and Super Safe Structures for the New Century, In: Proceedings of the First European Workshop on Structural Health Monitoring, Paris, July $10-12$, pp. 3-12.

2. Balageas, D.L. (2001). Structural Health Monitoring R\&D at the European Research Establishment in Aerospace (EREA), In: Proceedings of the 3rd International Workshop on Structural Health Monitoring: The Demand and Challenges, Stanford, September 12-14, pp. 12-29.

3. Chang, P.C. and Flatau, A. (2002). Health Monitoring of Civil Infrastructure, In: Proceedings of the First European Workshop on Structural Health Monitoring, Paris, July $10-12$, pp. $21-30$.

4. Alper, J.M. (1991). Structural Damage Detection for Smart Structures, In: Proceedings of Optical Sensors in the Control of Flexible Structures, sponsored by Virginia Tech, Blacksburg, VA, April 3-4 pp. 102-113.

5. Benussi, L., Berardis, S., Bertani, M., Bianco, S., Caponero, M.A., Colonna, D., Fabbri, F.L., Felli, F., Giardoni, M., La Monaca, A., Ortenzi, B., Pace, E., Pallotta, M., Paolozzi, A. and Tomassini, S. (2003). Fiber Optic Sensors for Space Missions, IEEE Aerospace Conference, March, Montana, USA.

6. Mrad, N., Melton, R.G. and Kulakowski, B.T. (1997). Performance of Optical Sensors in the Control of Flexible Structures, Journal of Intelligent Materials System and Structures, 8(11): 920-929.

7. Berkoff, T.A., Kersey, A.D. and Friebele, E.J. (1991). Absolute Strain Sensing Using Fiber Interferometry, In: Proceedings of Conference on Optical Fiber Sensor Based Smart Materials and Structures, sponsored by Virginia Tech, Blacksburg, VA, April 3-4, pp. 21-28.

8. Ghandi, M.V. and Thompson, B.S. (1992). Smart Materials and Structures, Chapman \& Hall, New York.

9. Udd, E. (1995). Fiber Optic Smart Structures, John Wiley \& Sons, Inc., New York.

10. Felli, F., Paolozzi., A. and Caponero, M.A. (2000). Fabrication of Intelligent Aluminum Matrix Composite, Aluminum Transaction, 2: 189-194. 
11. Paolozzi, A., Caponero, M.A., Felli, F., Tului, M. and Valente, T. (2000). Preliminary Tests for an Intelligent Thermal Protection System for Space Vehicles, In: Proc. of SPIE, Smart Materials, Vol. 4234, Melbourne, Australia, Dec. 2000, pp. 160-167.

12. Brotzu, A., Caponero, M.A., Colonna, D., Felli, F., Paolozzi, A. and Peroni, I. (2005). Environmental Tests on a Reinforced Concrete with Embedded FBG Sensors, In: 2nd JSME-ASME Int. Conf. on Materials \& Processing 2005 13th JSME Materials \& Processing Conf., Seattle, WA, USA, June 19-22.

13. Asanuma, H. and Kurihara, H. (1999). Possibility of Sensor Formation by Fracture of Pre-notched Optical Fiber in Matrix Materials, In: Dynamics and Design Conference, JSME, Vol. B, pp. 524-526.

14. Asanuma, H. (2002). Formation of Sensitive/Active Phases in Metal and Polymer Based Structural Materials, In: Proceedings of the SPIE: The International Society for Optical Engineering, 4934: 96-109.

15. Asanuma, H., Haga, O., Naito, N. and Tsuchiya, T. (1996). Development of an Actuator Utilizing Thermal Deformation of Ply Composites, Proc. Japan Society for Composite Materials, 19-20. 